\title{
An Analysis of Kenyan Learners' Proficiency in English Based on Reading Comprehension and Vocabulary
}

Logamurthie Athiemoolam \& Agnes Kibui

\begin{abstract}
In Kenya, English is the medium of instruction in schools and the official language of the country, although the majority of the learners are first additional language speakers of English. The study on which this article is based aimed to assess grade 10 Kenyan learners' proficiency in English by examining their performance in comprehension and vocabulary on the basis of three tests incorporating multiple choice and interpretative questions. The data were collected from 422 grade 10 learners representing 16 schools in four provinces of Kenya. Learners were assessed on three comprehension passages which were selected from different genres. The results revealed that a large percentage of Kenyan learners encountered challenges with comprehension and vocabulary which impacted on their English language proficiency. The implications of the study is that there is a need for a reading skills development programme incorporating word analysis, recognition of the purpose of the text and tone, and the enhancement of inferential as well as predictive and interpretive skills.
\end{abstract}

Key words: Reading Comprehension, English as Second Language Learners, Kenya

\section{Introduction}

Kenya is a highly diverse, multi-ethnic country comprising Africans and Asians who speak various mother tongues, Europeans of different nationalities, Arabs and other nationalities that come from diverse linguistic backgrounds (Kenyan Central Bureau of Statistics 1999). The African languages are traditionally regarded as belonging to four major linguistic groups which are; Bantu (for example, Gikuyu, Akamba, Luhya), Para-Nilotic (for example, Nandi, Kipsigis, Maasai), Cushitic (for example, Orma, Somali, Galla), and Nilotic (for example, Luo). Besides the respective mother tongues of the population Kiswahili is a common lingua franca, whilst English is the medium of instruction in primary school from grade 6 , secondary and tertiary institutions.

The participants in the research project speak their respective mother tongues, (that is, Gikuyu, Kalenjin, Luhya and Kikamba) and Kiswahili which they have acquired in and outside the classrooms. The acquisition of English, however, is quite different from Kiswahili as it is only learnt in schools where it is taught as a subject. This means 
that the subjects of the research project do not practise English after school because the lingua franca that is used in most homes is either Kiswahili or the vernacular. Most of these learners do not stay in their homes to read in the evenings because their families live in small, cramped rooms. Instead, they hang out with their friends in the neighbourhood where they speak pidgin English, known as 'sheng. This is a mixture of English, Kiswahili, and many local languages. According to Espelago (2001), peer pressure dictates that for one to belong and be accepted in a group, he/she must behave like it. Therefore, the Kenyan youth must speak 'sheng' as speaking English is unacceptable and is regarded as a formal way of communication. The speaking of 'sheng' hampers the development and mastery of English. Therefore, the environment at home does not assist these learners as they struggle to acquire the skills in English communication.

English as a medium of instruction plays a major role in Kenyan schools and institutions of higher learning, which makes it a determining factor in the learners' performance in other subjects. The advent of the 8.4.4 system of education, (that is, eight years in primary, four years in secondary, and four years in university) implemented by the Ministry of Education and the Kenya Institute of Education (KIE) about 20 years ago yoked English language to literature in what has been described as 'the integration approach'. The corollary of this is that certain important teaching methods like discussion, drills, dramatization and others are discarded in favour of those that can expressly meet the purpose of covering the syllabus. The major concerns expressed by teachers and learners are the overloaded English language syllabus and the 'integration approach' which provides limited time for the facilitation of reading comprehension and vocabulary skills.

Although Kiswahili is also a non-primary language for many Kenyans, the current language policy states that it should be introduced as a compulsory subject from kindergarten to Form IV (grade 12) as it is the national language in Kenya. Since there are many avenues and resources for learning Kiswahili both in and outside school the learners do not encounter problems mastering the language. On the other hand, the learning and mastery of English poses more complex challenges. The teaching and learning of English is problematic because the classroom is the only environment where the learner can hear and attempt to speak it. In this regard Gebhard (2000) points out that in English as second language settings there are fewer opportunities for learners to apply what they study to communicative situations outside the classroom since the only comprehensible English some of these learners hear and read is in the classroom. In the context of this study the Kenyan participants have limited exposure and reinforcement outside the classroom despite the fact that in Kenya, English assumes extra significance because it is the medium of instruction.

The merging of English and Literature in 1986 has had an adverse effect on both the teaching and learning of English and has led to poor performance in the Kenyan Senior Certificate Examinations (KSCE) as the syllabus is not adequately covered. One of the reasons is that English lost some 
lessons in the time-table to Literature and Kiswahili, thus making it difficult for the teachers to cover the syllabus efficiently and adequately. As a result, complaints have been raised about the declining standards of the English language. Muya (1993) for example articulates the general outcry by educationists, potential employers, and ordinary citizens who contend that most of the secondary school leavers and university graduates are not equipped with the basic skills in reading and writing in English.

In Kenya, there is a national concern for the problem encountered by children of all ages and levels of learning in comprehending written material. The ability to read with comprehension is a skill that is essential in modern society as learners are confronted with material on a daily basis that need to be read, analysed, interpreted and understood. Yet, a large number of people never master it completely. Comprehension is pivotal to reading as it occupies the central place on the continuum where input from the print and the reader is in central balance (Sadoski, 2004). Quite often, comprehension is difficult for second language readers because of cultural factors.

A study conducted by Gichaga (1986) on the factors that influence secondary school learners' performance in the English language at Kenyan Certificate School Examination level in two different districts indicated that reading comprehension constituted amongst the major challenges to learners. The findings also revealed that since learners' exposure to the English language was limited, they lacked the ability to express themselves adequately in spoken and written English.
Ellis (1999) and Coady (1993) point out that in second language learning formal instruction for vocabulary acquisition and comprehension is beneficial and suggest a mixed approach to vocabulary instruction in which basic vocabulary is explicitly taught along with strategies that will allow learners to deal effectively with less frequent vocabulary than they encounter in context so that such vocabulary can be learned when needed. Currently in the Kenyan context such formal instruction is not possible due to the implementation of the 'integrated approach' which essentially reduces the time available for formal instruction in vocabulary and reading comprehension skills.

\section{Objectives of the study}

The study aimed to examine Kenyan learners' proficiency in English with specific reference to their comprehension and vocabulary skills by means of quantitative measures and to identify challenges experienced by learners relating to these sub skills.

\section{The Hypotheses of the study}

\section{Hypothesis I}

There is a low level of proficiency in the interpretative skill in reading comprehension of Form IV learners.

\section{Alternative Hypothesis}

There is a high level of proficiency in the interpretative skill in reading comprehension of Form IV learners.

\section{Hypothesis II}

There is a low level of proficiency in vocabulary of Form IV learners. 


\section{Alternative Hypothesis}

There is a high level of proficiency in vocabulary of Form IV learners.

\section{The study}

The study focused on an analysis of Kenyan learners' proficiency in English with specific reference to the two sub skills namely reading comprehension and vocabulary. The data was collected from learners representing 16 schools in four provinces of Kenya on the basis of three comprehension passages selected from different genres. The details of the study are briefly presented here:

\section{Methodology}

This study was conducted using quantitative research methodology. According to Reaves (1992), Fraenkel and Wallen (1996), quantitative research is a study that involves measuring quantities of things, usually numerical quantities and its purpose is to describe a particular situation or event.

The aim of this study was not to judge but to identify the level of proficiency in comprehension and vocabulary skills by testing and reporting observations of subskills by quantifying the findings. The study was also correlational as it intended to investigate the relationship if any, between the two sub-skills of the group in the sample. The data are reported in terms of scores with higher scores indicating that more of the variable is present than do lower scores.

\section{Population}

The population comprised Form IV learners from secondary schools in Kenya. From this population the sample was selected from 16 schools. That is, four schools from each of the four provinces sampled were used for the study. The sample was selected from Form IV learners for the following reasons:

(i)Forms, I, II, III would not have completed the syllabus as indicated in KCSE Syllabus (2000-2001:22). 'At this level, the learners' vocabulary is limited. Therefore, the selection of the materials intended to develop the learners' vocabulary should be done very carefully."

(ii)Form IV learners were the most suitable class as they had completed the syllabus. "The learner will have acquired a wider range of vocabulary than he/she had in Form I, II, and III. He/She therefore should be exposed to more difficult reading materials and a wider range of register using the activities suggested in Forms I, II and III." (KCSE, 2000-2001:22)

There are eight provinces in Kenya which are Nairobi, Central, Coast, Eastern, North Eastern, Rift Valley, Nyanza, and Western. This study consisted of one stage stratified random sampling of four provinces out of eight. That is, using the procedure, Nairobi and Western were selected to represent the high performing provinces while Eastern and the Rift Valley represented the low

TABLE 1.1:NUMBER OF ITEMS PER COMPREHENSION

\begin{tabular}{|l|l|l|l|l|l|l|}
\hline & $\begin{array}{c}\text { Part I vocabulary } \\
\text { multiple choice }\end{array}$ & $\begin{array}{c}\text { Part II vocabulary } \\
\text { inferential }\end{array}$ & $\begin{array}{c}\text { Part III comprehension } \\
\text { multiple choice }\end{array}$ & $\begin{array}{c}\text { Part IV comprehension } \\
\text { inferential }\end{array}$ & $\begin{array}{c}\text { Total No. of } \\
\text { items }\end{array}$ & $\begin{array}{c}\text { Total No. of items } \\
\text { for all tests }\end{array}$ \\
\hline Test A & 5 & 5 & 5 & 5 & 20 & \\
\hline Test B & 5 & 5 & 5 & 5 & 20 & \\
\hline Test C & 5 & 5 & 5 & 5 & 20 & 60 \\
\hline
\end{tabular}


performing provinces. The classification was based on the KCSEE (Kenyan Certificate of Secondary Education) results for the last five years (Daily Nation: 2001, 2002, 2003, 2004 and 2005). The four provinces were 50 per cent of the total number of provinces in Kenya. This gave the study a fair chance for each province.

\section{Description of research instruments and data collection}

The instruments consisted of three reading comprehension tests namely: Tests A, B, and C. Each comprehension was divided into four sub-tests in terms of sections. While Part I and part III comprised multiple choice questions that tested comprehension and vocabulary respectively, Part II and IV consisted of inferential questions which tested the same sub skills. The three tests were administered among Form IV learners by the researcher with the help of a research assistant. The answer sheets for the three test papers were collected for analysis. The instruments were developed by the researcher who took into consideration the level of the learners and the requirements expected for good performance in the examination and proper communicative purposes during school and after completion of school.

The tests were designed to measure comprehension and vocabulary, which are aspects of the school curriculum in Kenyan secondary schools, through a sample of texts that were suitable for the level of the learners in Form IV. The learners in this study were familiar with the content of the three passages as the cultural setting was taken into consideration. Since the questions required learners to infer the message from the context and recognition of the writer's purpose and tone the learners' schemata were required in all the questions.

The comprehension and vocabulary questions were prepared using guidelines by Palinscar and Brown (1984) focusing on daily comprehension assessment, Barrett (1995) taxonomy of reading comprehension about "comprehension questions", Cheryl (1997) taxonomy of evaluating reading comprehension in EFL (English as a foreign language) about "multiple choice and inferential questions", Tierney (1998) in Block et al (2004) "ten principles concerning comprehension assessment", and Hamday (2002:12-14) four forms of standardized tests under "Typical Reading Comprehension Questions", which are:

(a)Questions based on the entire passage.

(b)Questions based on sections of the passage.

(c)Questions based on words, phrases, or sentences.

Each of the above sections was given equal attention and marks. Learners answered questions about the gist of the passage, the author's intention, main ideas, and content (the entire passage). The instruments consisted of three reading comprehension tests namely: reading comprehension $\mathrm{A}, \mathrm{B}$, and $\mathrm{C}$. which were divided into four subtests in terms of sections as follows:

a. Part I comprised 5 multiple-choice questions that tested comprehension.

b. Part II consisted of 5 inferential questions that tested comprehension.

c. Part III had 5 multiple-choice vocabulary questions that tested 
Table 1.2: Correlations: Vocabulary scores compared

\begin{tabular}{|l|l|l|l|l|}
\hline & \multicolumn{1}{|c|}{$\begin{array}{c}\text { Multiple Choice } \\
\text { Vocabulary Scores }\end{array}$} & \multicolumn{1}{|c|}{$\begin{array}{c}\text { Inferential Vocabulary } \\
\text { Scores }\end{array}$} & $\begin{array}{c}\text { Inferential } \\
\text { Comprehension Scores }\end{array}$ & $\begin{array}{c}\text { Multiple Choice } \\
\text { Comprehension Scores }\end{array}$ \\
\hline Pearson Correlation & 1 & $.580(*)$ & $.540^{(* *)}$ & $.475\left({ }^{* *}\right)$ \\
\hline Sig. (2-tailed) &. & .000 & .000 & .000 \\
\hline N & 422 & 422 & 422 & 422 \\
\hline Pearson Correlation & $.580(* *)$ & 1 & $.628(* *)$ & $.585(* *)$ \\
\hline Sig. (2-tailed) & .000 &. & .000 & .000 \\
\hline N & 422 & 422 & 422 & 422 \\
\hline Pearson Correlation & $.540(* *)$ & $.628(* *)$ & 1 & $.575(* *)$ \\
\hline Sig. (2-tailed) & .000 & .000 &. & .000 \\
\hline N & 422 & 422 & 422 & 422 \\
\hline Pearson Correlation & $.475(* *)$ & $.585(* *)$ & $.575(* *)$ & 1 \\
\hline Sig. (2-tailed) & .000 & .000 & .000 &. \\
\hline N & 422 & 422 & 422 & 422 \\
\hline
\end{tabular}

${ }^{* *}$ Correlation is significant at the 0.01 level (2-tailed).

vocabulary.

d. Part IV consisted of 5 inferential questions that tested vocabulary.

The three comprehension tests were based on multiple choice and inferential format as shown in Table 1.

This variety of sub-tests of multiple-choice and inferential questions in comprehension and vocabulary was required for the elimination of any guessing of the answers. That means, if a learner guessed in the multiple choice sections, he/she would be required to display his/her proficiency in the inferential sections where explanation of the answers was required.

These three subtests tested the following abilities:

1. The ability to follow instructions and to select the correct answer.

2. Remembering word meanings.

3. Drawing inferences about the meaning of a word from context.

4. Drawing inferences from content.
5. Using effective reading strategy to assist comprehension.

6. Finding answers to questions answered implicitly or explicitly from the context.

7. Recognizing the writer's purpose, attitude, tone and mood

The scoring was done as follows: every correct response was awarded 2 marks (the coding for correct response was 1 , and incorrect response was 2); no marks were awarded for any blank or incorrect response. Since each of the three passages had 20 questions the total score was 40 marks per passage. The total marks for each comprehension was converted into percentiles.

\section{Data analysis}

Non-parametric method Binomial tests using Statistical Package for Social Sciences (SPSS) was used to test hypotheses one and two. The hypotheses were: There is a low level of proficiency in the interpretive skill in reading comprehension of form four learners and there is a low level of proficiency in 
vocabulary of Form IV learners respectively. A variable with two levels was created using the KNEC's (Kenyan National Education Commission's) 2006-2007 formula. That is, Low proficiency: 0-54; High proficiency: 55-100. In language studies, the significant level is set at $\mathrm{p}<.01(1 / 100)$ or at $\mathrm{p}<.05$ $(5 / 100)$, depending on whether the researcher is willing to accept only 1 percent error or up to 5 percent error, respectively (Brown, 1988:116). In this research, the null-hypothesis is test proportion 0.5, that is, 50 percent equal. The significant level of the test is 0.05. Pearson ChiSquare test was used to test dependence of the two variables. The two variables were proficiency in comprehension and vocabulary. The significant level used was 0.05 . That means that if the probability value was less than 0.05 , the null hypothesis was rejected. Descriptive statistics was used to analyze the scores. Minimum and maximum scores were analyzed by the use of tables, graphs and percentiles.

\section{Multiple choice and inferential vocabulary scores}

Scores of multiple choice vocabulary questions of the three comprehensions were added together for each learner. A percentage was calculated in order to acquire a general view of all the learners by the use of percentiles, graphs, and tables. The use of the percentages assisted in the calculation of the range of scores, that is, the largest score, and the smallest one. The same procedure was used to calculate scores of inferential vocabulary questions which was done in order to compare the learners' performance in the two sub-tests.

\section{Results}

The multiple choice comprehension scores for each test were obtained and compared with the inferential scores. The mean was obtained and a comparison was made between the two scores in comprehension. The same comparison was done for the two vocabulary scores as shown in Table 2.

A correlation exists between the following scores:

(a)Multiple Choice Vocabulary Scores and inferential Vocabulary Scores of 0.580.

(b)Multiple Choice Comprehension Scores and inferential Comprehension Scores of 0.575

(c)Multiple Choice Vocabulary Scores and Multiple Choice Comprehension Scores of 0.475 .

(d)Inferential Vocabulary Scores and inferential comprehension Scores of 0.628

(e)Inferential Vocabulary Scores and Multiple Choice Comprehension Scores of

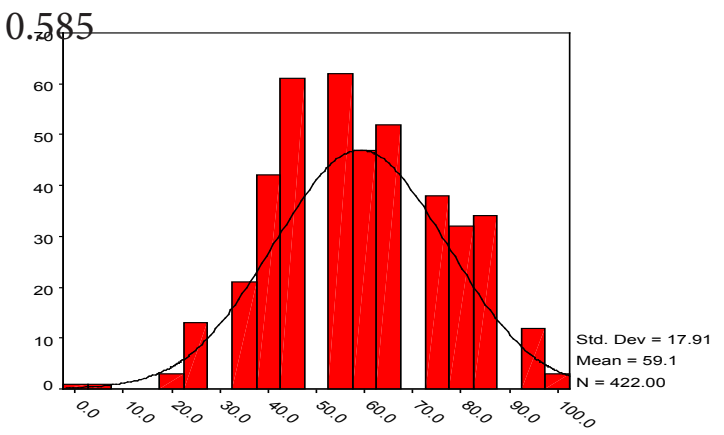

Figure 1.1: Multiple choice Comprehension Scores of Tests $A, B$ and $C$

Multiple choice comprehension scores appear to be normally distributed with a mean score of 59.1 and standard deviation of 17.91 . 


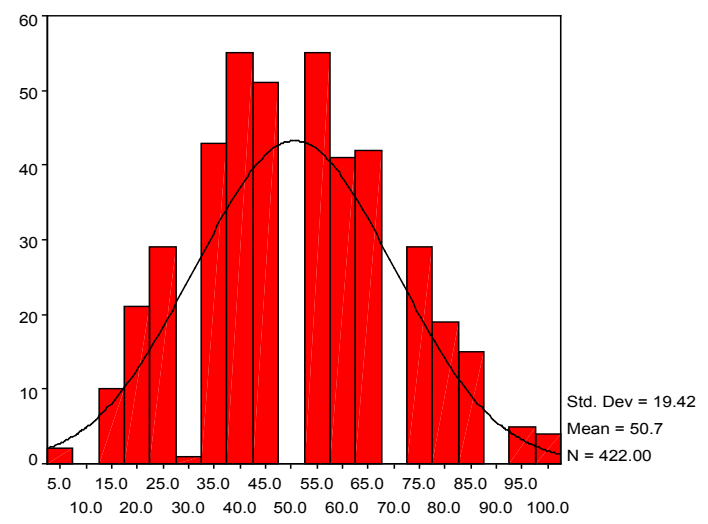

Figure 1.2: Inferential Comprehension Scores of Tests A, B and C

Inferential comprehension scores appear to be normally distributed with a mean of 507 and ctandard dariation of 1040

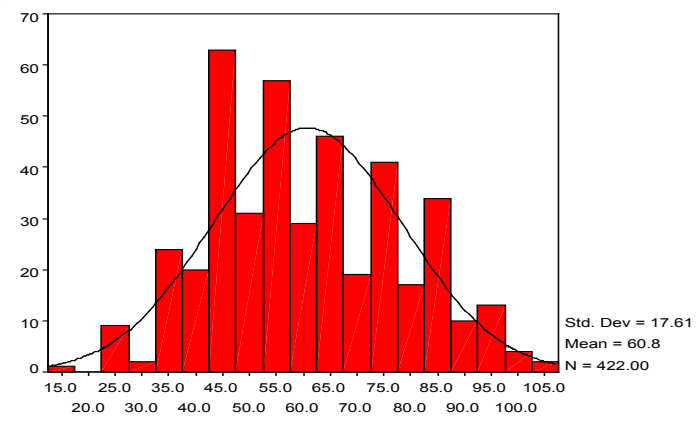

Figure 1.3: Results of all comprehension scores of the three tests

The scores appear to be normally distributed with a mean of 60.8 and standard deviation of 17.61

Table 1.3: Descriptive Statistics

\begin{tabular}{|l|c|l|l|l|l|}
\hline & N & Mean & Std. Deviation & Minimum & Maximum \\
\hline Grading Results & 422 & 1.60 & .490 & 1 & 2 \\
\hline
\end{tabular}

Table 1.4: Binomial Test

\begin{tabular}{|l|l|l|l|l|l|}
\hline & Category & $\mathrm{N}$ & $\begin{array}{l}\text { Observed } \\
\text { Prop. }\end{array}$ & Test Prop. & $\begin{array}{l}\text { Asymp. } \\
\text { Sig. } \\
\text { (2-tailed) }\end{array}$ \\
\hline Group 1 & High & 167 & .40 & .50 & $.000(\mathrm{a})$ \\
\hline Group 2 & Low & 255 & .60 & & \\
\hline Total & & 422 & 1.00 & & \\
\hline
\end{tabular}

Based on Z Approximation.

Hypothesis I that there is a low level of proficiency in comprehension of Form IV learners has been accepted. With a test proportion level of 0.50 the results indicate that $40 \%$ have a high level of proficiency in comprehension while $60 \%$ of the learners have a low level of proficiency in comprehension. Since the test proportion of 0.50 is more than the significant level of 0.000 Hypothesis I can be accepted. The alternative hypothesis has been rejected since the significant level is 0.000 which is less than 0.05 .

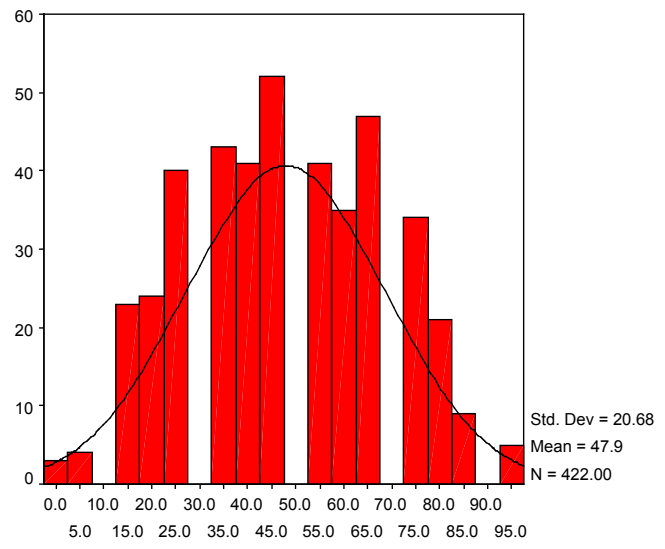

Figure 1.4: Multiple choice Vocabulary Scores

Multiple choice vocabulary scores appear to be normally distributed with a mean of




Figure 1.5: Inferential Vocabulary Scores

Inferential vocabulary scores appear to be normally distributed with a mean of 47.9 and standard deviation of 3068

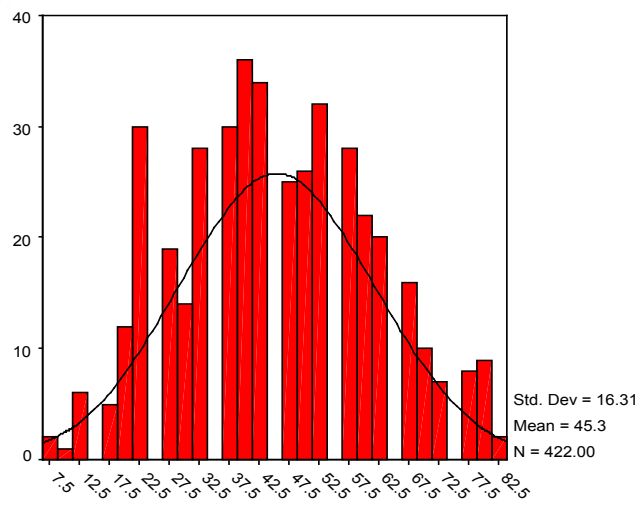

Figure 1.6: Results of all vocabulary scores of the three tests

Scores of all comprehension scores of the three tests appear to be normally distributed with a mean of 45.3 and standard deviation of 16.31 .

Table 1.5: Descriptive Statistics

\begin{tabular}{|l|l|l|l|l|l|}
\hline & \multicolumn{1}{|c|}{ N } & \multicolumn{1}{|c|}{ Mean } & $\begin{array}{c}\text { Std. } \\
\text { Deviation }\end{array}$ & Minimum & Maximum \\
\hline Vocabulary Scores & 422 & 1.71 & .454 & 1 & 2 \\
\hline
\end{tabular}

Table 1.6: Binomial Test: Vocabulary scores

\begin{tabular}{|l|l|l|l|l|l|}
\hline & Category & \multicolumn{1}{|c|}{$\mathbf{N}$} & $\begin{array}{c}\text { Observed } \\
\text { Prop. }\end{array}$ & Test Prop. & $\begin{array}{c}\text { Asymp. Sig. } \\
\text { (2-tailed) }\end{array}$ \\
\hline Group 1 & High & 300 & .71 & .50 & $.000(\mathrm{a})$ \\
\hline Group 2 & Low & 122 & .29 & & \\
\hline Total & & 422 & 1.00 & & \\
\hline
\end{tabular}

Based on $Z$ Approximation.

Hypothesis II that there is a low level of proficiency in vocabulary of Form IV learners has been accepted. With a test proportion level 0.50 the results indicate that $29 \%$ of the learners have a high level of proficiency in vocabulary while $71 \%$ have a low level of proficiency in vocabulary. Since the test proportion level of 0.05 is more than the significant level of 0.000 , Hypothesis II can be accepted. Therefore the alternative hypothesis has been rejected since significant level is 0.000 which is less than 0.05 .

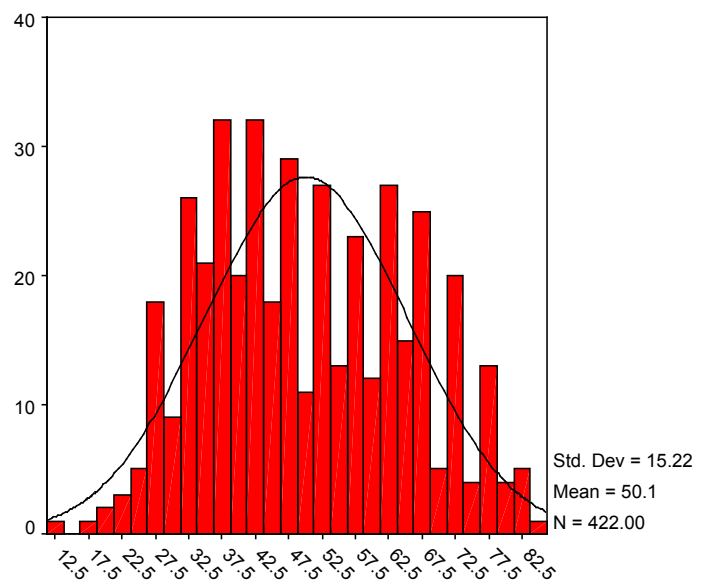

Figure 1.7: Combined Results of the scores of the three tests

The results of all the three tests appear to be normally distributed with a mean of 50.1 and standard deviation of 15.22

Table 1.7: Correlations: Comprehension and Vocabulary

\begin{tabular}{|l|l|l|}
\hline & $\begin{array}{c}\text { \%All Comprehension } \\
\text { Scores }\end{array}$ & \%All Vocabulary Scores \\
\hline Pearson Correlation & 1 & $.768\left(^{* *}\right)$ \\
\hline Sig. (2-tailed) &. & .000 \\
\hline N & 422 & 422 \\
\hline Pearson Correlation & $.768\left(^{* *}\right)$ & 1 \\
\hline Sig. (2-tailed) & .000 &. \\
\hline N & 422 & 422 \\
\hline
\end{tabular}

${ }^{* *}$ Correlation is significant at the 0.01 level (2-tailed).

The results of the three tests revealed that many factors affect comprehension. Among the factors are: failure to follow instructions; failure to refer to the context of the text as required by the questions; failure to make calculated guesses in multiple choice questions; application of 
wrong schemata; and a lack of background knowledge. Below is an analysis of some of the incorrect responses provided by the learners and an interpretation of their responses:

In response to a question from text A: " $D i d$ the author regard Chumley as handsome? Give reasons for your conclusion". A number of students responded incorrectly as they thought that 'terrific personality' was a sign of beauty. Others thought that the chain he wore was beautiful and so was part of his beauty. Otherwise the answer was explicitly stated in the passage that is, "although he was not exactly a nice chimp to look at (I had seen more handsome). Their incorrect responses indicate that there was a failure on the learners' part to refer to the context of the text as required by the question.

In response to another question: "What was it about Chumley that made the author feel inferior?" $35.1 \%$ answered correctly. The answer is implied in paragraph two that is, his intelligence and terrific personality. The majority of those who responded incorrectly wrote, "the way he surveyed the surrounding" but failed to understand that this only made the author feel embarrassed about the condition of the hut but not inferior. The answer required analysis and reasoning which seemed to be lacking on their part.

In response to the question based on text A: "Which part of Songhai did Kisimi come from?" those who responded incorrectly wrote that "Kisimi came from Lokko in Songhai". They did not understand that 'Lokko' was the tribe and not the location. This is a demonstration of the application of the incorrect schemata.
A further example of limited reasoning skills is evident in their responses to the question: "What made the author feel brave?" The majority of them were unable to identify the correct response as: "There were plenty of people who could give him support". This is implicitly stated in paragraph one. The answer needed reasoning in order to understand the question as the word 'support' was the guiding cue. It emerged from this example that a number of learners were unable to identify context clues in a reading text.

\section{Discussion of findings}

The responses to the questions provided by many of the learners revealed that Form IV Kenyan learners do not have a wide knowledge of the world and the English language, consequently the schemas they had to draw from was a limiting factor in the three tests. Adequate context provided them with immediate clues for guessing while insufficient context and a low proficiency in vocabulary and comprehension led to mismatches in word analysis and recognition that caused confusion and misinterpretation of the texts.

These test strategies reveal that a respondent might perform highly or poorly not because of his cognitive ability but the ability to respond wisely to instructions and questions. For example, in the case of this study the participants were familiar with some of the items in the test but applied their schemas without referring to the instructions and the text especially in the vocabulary section. That means they did not construct accurate literal interpretations as they just explained 
the meaning of the words from their experiences and not from the text as was required. In Test A question 5 'make-up", the correct answer was (B), "character". Although $74.2 \%$ circled the correct answer, those who responded incorrectly circled (D) "cosmetics". The answer was clearly stated in the last paragraph from the chimpanzee's behaviour and the guiding word 'vices'. Some of the other vocabulary that they interpreted incorrectly due in part to their lack of skills in identifying context clues included "rude shock", "terrific" which they interpreted as terrifying, " ducked", "fumbled" and they described "roared out" as "walked out".

The learners who gave incorrect responses provided dictionary meanings without due regard to the context and therefore failed to understand the message. This was an example of incorrect use of background knowledge and poor test strategies. Some learners took short cuts to arrive at the answers and they did not read the text as was required in order to understand the content. In reading comprehension, word decoding alone without understanding the meaning is not adequate. In this regard as highlighted by Scheckle (2009) in Ferreira (2009) for learners to read successfully they need a combination of decoding and understanding where they are able to use their knowledge of letters and words to make sense of what they read. In order for comprehension of written text to take place, readers must infer or deduce meaning from the text using the words written by the author. In this sense just sounding out words aloud is limited if there is no understanding of what is being read.

In a study on word recognition, transfer, and reading acquisition, Compton (2005) found that skilled comprehension readers are rapid at word decoding than less skilled readers. He also found that the establishment of decoding skills through structured intervention acted as a boot strapping mechanism to improve reading skills, such as word recognition skill, reading fluency, and comprehension. This is an indication that skilled readers are able to use their skills in reading for meaning rather than for word recognition only. Reading for meaning depends upon vocabulary knowledge, syntactic integration, inferences, and other higher order overlapping skills that make demands on the same mechanism responsible for converting the printed code into the language code.

These findings are supported by a study on the role of comprehension of meaningful language input in young adults' second language learning by Paribakht, and Wesche (1992). Their study indicated superior gains in the comprehension-based class in text comprehension and discourse processing, despite smaller gains in grammatical knowledge. This finding was on the 'use of introspection in exploring links between comprehension of meaning and acquisition of vocabulary'. This suggested that explicit grammar instruction is not needed to enhance comprehension skills, but vocabulary knowledge is important. A further study by Koda and Keiko (1989) on the examination of effects of transferred vocabulary knowledge on the development of second language reading on Japanese college learners indicated that vocabulary knowledge was highly correlated with reading comprehension. These research 
findings resonate with this study in that it also highlights the significant role that vocabulary plays in terms of text analysis but more specifically in relation to the context clues within a text.

\section{Implications of the findings}

From the findings of the study, there appears to be a need for a reading intervention programme across all schools incorporating all the skills that are required for effective reading comprehension. There is a need to build an adequate sight vocabulary by exposing the learners to a variety of texts, genres, content areas, and styles of writing. Word analysis should be taught, and the reading programme should focus on the development of inferential, predictive, and interpretive skills.

\section{Conclusion}

It is evident from the study that Kenyan learners are experiencing challenges with the interpretation and application of reading comprehension and vocabulary skills that are essential to the promotion of effective reading with the focus on meaning making.

Some reading difficulties experienced by the learners within the context of this study could be attributed to problems external to the reader which could include a lack of background knowledge, the way texts are written and organized, the style and complexity of the language, an impoverished reading culture and environment, and inadequate experience and exposure to the manifold contexts in which reading occurs. Moreover, poor teaching can both initiate and perpetuate reading difficulties for learners. That means teachers should use teaching methods that would improve their learners' predictive and interpretive skills relating to reading comprehension.

Finally, learners should be aware that becoming a good reader takes time and involves sustained reading effort. With guidance and support from their teachers and a great deal of exposure to different genres, learners will, over time, have the opportunity to become proficient readers with enhanced interpretive, critical and analytical skills.

\section{About the authors}

Dr. Logamurthie Athiemoolam is a senior lecturer in the Faculty of Education at the Nelson Mandela Metropolitan University in Port Elizabeth, where he trains teachers to teach English at home and first additional language levels and presents modules in multicultural education, English language proficiency and language across the curriculum. His fields of research are English second language teaching, drama-in-education and multicultural education. He has coedited a book on drama-in-education with Professor Wolfgang Nitsch from the University of Oldenburg in Germany entitled 'North-South- Cooperation in In-Service Teacher Training'. Currently he is Head of the ACE-LLT (Language in Learning and Teaching) Programme in the Faculty of Education.

Dr. Agnes Kibui is a senior lecturer in the Faculty of Education at the University of Nairobi in Kenya where she is engaged in training teachers to work in secondary schools. Her fields of expertise and research are English language teaching and linguistics and she has extensive experience in empowering pre-service teachers to teach English as a second language in secondary schools in Kenya. She has written a number of articles on English second language teaching and didactics.

\section{References}

Barret, G. (1995). Reading comprehension; "Comprehension Questions" and the whole issue of checking understanding. Teacher link, vol. 2, issue (March 1995). Retrieved on $25^{\text {th }}$ June 2011 from http://www.mgu.ac.jp/-ic/helgesen/ marc.article 1.htm

Block, C.C., Rodgers. L.L., \& Johnson, R.B. (2004). Comprehension Process Instruction. New York: 
The Guilford Press.

Brown, J.D. (1988). Understanding research in second language learning. New York: Cambridge University Press.

Cheryl, L. (1997). Evaluating reading comprehension: multiple choice and inferential E.F.L. 35( 2), 20-35.

Coady, J. (1993). Research on ESL/EFL vocabulary acquisition: Putting it in context. In T. Hucklin; M. Haynes; and J. Coady (Eds.), Second language reading and vocabulary learning (pp. 3-23). Norwood, N.J.: Ablex.

Compton, D.L. (2005). Putting transfer back on trial: Modeling individual differences in the transfer of decoding-skill gains to other aspects of reading acquisition.

Daily Nation (1991, 2000, 2001, 2002, 2003, 2004, 2005). Kenya Certificate of Secondary Education Results. Nairobi: The Daily Nation.

Ellis, R. (1999). Learning a second language through interaction. Philadelphia: John Benjamins Publishing Co.

Espelago, D.L., and Holt M.K. (2001). Bullying and victimization during early adolescence: Peer influences and psychological correlates (pp123142). Binghamton: MY, Haworth Press.

Fraenkel, J.R. \& Wallen, N.E. (1996). How to design and evaluate research in education. New York: McGraw-Hill, Inc.

Gebhard, J.G. (2000). Teaching English as a foreign or second language. A teacher self-development and methodology guide. Michigan, U.S.A.: The University of Michigan Press.

Gichaga, M. (1986). A study of the factors that influence performance in English language at the Kenya Certificate of education in Kiambu District. Unpublished M.ED Thesis, Kenyatta University.

Hamday, A.T. (2002). General purpose learning strategies: Reading comprehension. New York.:
Tora.

Kenyan Central Bureau of Statistics. (1999). Republic of Kenya: 2001. Population and Housing Census (vol. 1) Jan 2001 Nairobi: Government Press.

Koda and Keiko. (1989). The effects of transferred vocabulary knowledge on the development of $L 2$ reading proficiency. Retrieved on August 282008 from http://web28.epmet.com 85-975.

Muya, W. (1993). "Why varsity graduates are illiterate." Nairobi: The Daily Nation, $20^{\text {th }}$ June.

Palinscar, A. and Brown, A. (1984). Reciprocal teaching of comprehension and comprehension monitoring activities. Illinois: University of Illinois

Paribakht, T. S and Wesche, M, B. (1992). A methodology for studying the relationship between comprehension and second language development in a comprehension-based/ ESLProgram. Retrieved on September 20, 2011 from http://web28.epnet.com

Reaves, C.C. (1992). Quantitative research for the behavioural sciences. New York: John Willy \& Sons, Inc.

Sadoski, M. (2004). Conceptual foundations of teaching reading. New York: The Guilford Press.

Scheckle, E. (2009). Strategies and practices for effective reading. In A Ferriera (Ed.), Teaching language (pp. 133-147). Gauteng: Macmillan.

The Kenya Institute of Education. (1990). The English syllabus for secondary schools. Nairobi: K.I.E.

The Kenya National Examinations Council. (1993, 2000, 2003, 2005). Candidates' performance Report. Nairobi: The Kenya National Examinations Council.

The Kenya National Examinations Council. (1997, 2000, 2002, 2005,\& 2006-2007). The Kenya National Examinations Council; Regulations and Syllabus. Nairobi: The Kenya National Examinations Council. 